\title{
ECONOMIA DE ESCALA NO PROCESSO DE RESFRIAMENTO DO LEITE
}

\author{
Economies of scale in the milk cooling process
}

\author{
Marcela de Mello Brandão Vinholis ${ }^{1}$, Humberto de Mello Brandão ${ }^{2}$
}

\begin{abstract}
RESUMO
Objetivou-se, neste artigo, estimar os custos envolvidos no processo de resfriamento do leite cru, tipo B, após a implantação da Instrução Normativa 51 e a verificação das possíveis fontes de economias de escala nesse processo. A partir dos conceitos da engenharia econômica calculou-se o custo uniforme líquido equivalente de investimento do processo de resfriamento do leite, que somado ao custo operacional, resultou no custo uniforme líquido total por litro de leite. Concluiu-se que existe forte tendência à economia de escala nessa atividade devido aos retornos crescentes no custo de investimento e operacional, conforme aumenta-se a capacidade dos tanques de resfriamento.
\end{abstract}

Termos para indexação: Gado leiteiro, refrigeração, custo de produção.

\begin{abstract}
This article aims to estimate the costs involved in the milk cooling process after the Normative Instruction 51 was issued and it also aims to verify the sources of economies scale. Using the concepts of the economical engineering, the uniform net costs of the investment in the milk cooling process were calculated. They were added to the operational cost and it resulted in the total uniform net cost per unit. It was concluded that there is a strong tendency to economies scale in the milk cooling process as a consequence of the growing returns in the investment and operational costs as the milk cooling tank capacity increases.
\end{abstract}

Index terms: Dairy cattle, cooling process, production cost.

(Recebido em 14 de novembro de 2007 e aprovado em 9 de julho de 2008)

\section{INTRODUÇÃO}

A economia de escala foi definida como aquela resultante do aumento do tamanho de uma única unidade de produção ou distribuição de um único produto e, por conseqüência desse aumento de escala, a redução do custo unitário de produção ou distribuição. As economias de escala, em indústrias mais antigas, dava-se pela intensificação do trabalho, obtido pelo aumento do número de equipamentos e funcionários para operá-los. As indústrias recentes são caracterizadas por serem mais intensivas em capital e o aumento da produção deve-se à: (i) melhorias e reorganização da matéria-prima; (ii) equipamentos e habilidades melhoradas; (iii) reorientação do processo de produção e; (iv) aumento da energia empregada. São exemplos das indústrias mais recentes o processo de produção do açúcar, petróleo, óleo vegetal e animal, tabaco e outros produtos agrícolas (CHANDLER, 1990).

As economias de escala ditas reais ocorrem quando o fator que as explica é a redução na quantidade de fatores produtivos utilizados quando há um aumento da produção. As economias de escala pecuniárias são decorrentes da redução no preço pago pelo insumo, ou seja, os preços dos fatores de produção decrescem com o aumento das quantidades produzidas e não a quantidade consumida de insumos por unidade de produto (AZEVEDO, 1998; BAIN, 1956; KUPFER \& HASENCLEVER, 2002). Enquanto as economias de escala reais podem decorrer de diversos fatores, as pecuniárias, são normalmente derivadas da maior capacidade de barganha ou do menor risco decorrente do porte da empresa. Uma empresa operando em grandes volumes pode adquirir seus insumos a preços mais baixos, conseguindo impor aos seus fornecedores termos que atendam seu interesse (ARAÚJO, 2003; AZEVEDO, 1998).

De acordo com Chandler (1990) a utilização da capacidade plena da planta de produção é uma condição básica para a obtenção de vantagens de custo decorrentes das economias de escala. Se o volume estiver abaixo da capacidade, os custos efetivos por unidade tendem a crescer e as vantagens potenciais de custo podem não ser completamente realizadas. Nesse sentido, torna-se ainda mais importante a coordenação entre as diferentes atividades da empresa para que a utilização da capacidade plena da instalação possa ser atingida continuamente. Por

\footnotetext{
${ }^{1}$ Agrônoma, Mestre em Engenharia de Produção, Pesquisadora - Setor de Pesquisa - Embrapa Pecuária Sudeste - Rodovia Washington Luiz, Km 234 - Cx P. 339 - 13560-970 - São Carlos, SP - marcela.vinholis@cppse.embrapa.br

${ }^{1}$ Veterinário, Mestre em Zootecnia, Pesquisador - Setor de Pesquisa - Embrapa Gado de Leite - Rua Eugênio do Nascimento, 610 - $36038-330$ - Juiz de Fora, MG - humberto@cnpgl.embrapa.br
} 
ser a atividade leiteira dependente de fatores ambientais, há que se ter um bom controle das etapas anteriores ao processo de resfriamento do leite. Dentre elas destaca-se o controle sanitário do rebanho e o controle da produção e qualidade do alimento ofertado, de forma a reduzir a estacionalidade de produção e programar a suplementação com qualidade em períodos de seca. Dessa forma, minimizase a queda de produção de leite do rebanho nos meses de seca (abril a agosto).

O tema tem relevância significativa para o setor, em especial após a publicação da Instrução Normativa 51, que visa a melhor qualidade do produto final e exige a implementação desse processo por parte do pecuaristas. $\mathrm{O}$ estudo também tem importância para o processo de formulação estratégica da empresa rural e tomada de decisão, em especial no setor leiteiro que opera com margens estreitas e é tomador de preço no mercado.

Baixas temperaturas do leite armazenado retardam os processos químicos e o crescimento microbiano, evitando dessa forma a queda da qualidade do produto. Com base nesse conhecimento, foi promulgada a Instrução Normativa 51 (BRASIL, 2002), que tem por objetivo fixar requisitos mínimos para a produção, a coleta, o transporte a granel, a identidade e a qualidade do leite.

O escopo deste artigo restringe-se ao processo de resfriamento do leite cru tipo $\mathrm{B}$, o qual inicia-se com o enchimento do tanque após a ordenha dos animais e encerra-se no esvaziamento do tanque, no momento da coleta do leite pela indústria. Segundo o Ministério da Agricultura, Pecuária e Abastecimento, por meio da Instrução Normativa 51, entende-se leite cru refrigerado tipo B, o produto integral quanto ao teor de gordura, refrigerado em propriedade rural produtora de leite e nela mantido pelo período máximo de $48 \mathrm{~h}$, em temperatura igual ou inferior a $4^{\circ} \mathrm{C}$, que deve ser atingida no máximo $3 \mathrm{~h}$ após o término da ordenha, transportado para estabelecimento industrial, para ser processado, onde deve apresentar, no momento do seu recebimento, temperatura igual ou inferior a $7^{\circ} \mathrm{C}$. Esse processo requer a estrutura da "Sala de leite", onde deve ser instalado o equipamento de refrigeração em placas ou por expansão direta.

O resfriamento do leite na propriedade rural tem por objetivo inibir o crescimento bacteriano e prolongar o armazenamento do produto na propriedade rural de forma a reduzir os custos de transporte e evitar a perda da qualidade do produto. $\mathrm{O}$ crescimento de bactérias no leite é reduzido em meio do rápido resfriamento abaixo de $10^{\circ} \mathrm{C}$, atingindo a sua eficiência máxima em temperaturas próximas de 3 a $4^{\circ} \mathrm{C}$.
A ação bacteriana induz a alterações fisico-químicas no leite, que levam a perdas econômicas ao longo de toda a cadeia produtiva, destacando a queda no rendimento industrial, o aparecimento de problemas de processamento e a produção de derivados lácteos mais instáveis, de pior qualidade e com menor vida de prateleira (CARVALHO et al., 2007). Entretanto, grande parte do ônus recai sobre o consumidor final, que pode ficar exposto a toxinas bacterianas termo-estáveis, freqüentemente associadas a surtos de toxinfecção alimentar (FAGUNDES \& OLIVEIRA, 2004).

A qualidade final do produto, depende, dentre outros fatores, da qualidade inicial bacteriológica do leite. Essa qualidade inicial é consequiência da sanidade do animal e das condições de limpeza e desinfecção do equipamento de ordenha e do ambiente onde o leite é colhido e armazenado. Portanto, o processo de resfriamento do leite trata de um complemento das condições de higiene necessárias para a qualidade do produto final.

Conforme consulta realizada junto a fabricantes de tanques de resfriamento de leite e verificado na literatura (MELO, 2003), o sistema por expansão direta que utiliza o tanque cilíndrico é atualmente o mais utilizado pelos produtores rurais de leite. $\mathrm{O}$ fundo do tanque é projetado como um evaporador, sendo que o calor do leite passa pela parede de aço inoxidável para o meio de resfriamento, que ao se expandir, evapora removendo o calor do leite sob agitação. A instalação de tanques de resfriamento do leite exige ainda energia elétrica disponível e instalação específica para o armazenamento do equipamento, de preferência próxima ao processo de ordenha dos animais.

Objetivou-se, neste artigo, estimar os custos e verificar a presença e importância dos ganhos de escala no processo de resfriamento do leite cru tipo B, na propriedade rural da região de São Carlos (SP).

\section{MATERIAL E MÉTODOS}

A estimativa de custos foi realizada a partir de um levantamento junto a dois fornecedores, representativos no mercado nacional de tanques de resfriamento de leite, sobre as características técnicas - capacidade, necessidade de instalação, manutenção, consumo de energia - e o preço de venda de cada modelo vertical ou horizontal que funcionasse pelo sistema de expansão direta. Na Fazenda Canchim, da Embrapa Pecuária Sudeste, localizada em São Carlos (SP), foi acompanhada a operação de enchimento do tanque, armazenamento e coleta do leite resfriado, em uma cooperativa sediada no município de Ribeirão Preto (SP). Esse acompanhamento foi realizado visando a quantificação de mão-de-obra e material de limpeza 
necessários no processo. Ainda foram realizadas entrevistas com funcionários da fazenda, da cooperativa e dos fornecedores dos tanques, que colaboraram para a identificação dos benefícios e das fontes de economia de escala, no processo de resfriamento do leite na propriedade rural.

Do levantamento junto a fornecedores, resultou uma relação de 11 modelos de tanques de resfriamento, com capacidades de 300, 500, 800, 1000, 1020, 1500, 2000, 3000, 4000, 5000 e 5900 litros de leite e que podem trabalhar em duas categorias: (i) tanques que se tornam cheios com o leite coletado a partir de 2 ordenhas e, (ii) tanques que são abastecidos com o leite coletado de 4 ordenhas das vacas em lactação. Em geral, as propriedades rurais da região do estudo possuem vacas de raças especializadas e realizam uma ordenha do leite no período da manhã e uma no período da tarde. Para o tanque que é abastecido com 4 ordenhas, a coleta do leite é realizada em dias alternados (a cada 48 horas), enquanto o tanque que é cheio com 2 ordenhas pode receber visita diária do caminhão. A coleta de leite diária ocorre em algumas propriedades que se encontram geograficamente próximas ao laticínio e possuem capacidade de armazenamento de leite em tanques de expansão inferior à produção total de dois dias. Esse fato é usado pelo laticínio para viabilizar a captação do leite de produtores pertencentes a linhas de coleta, que sozinhos, não atingiriam o volume mínimo necessário para a manutenção de um caminhão transportador.

O equipamento que atinge sua capacidade máxima com o leite coletado de 2 ordenhas contempla as fases: vazio, $50 \%$ e $100 \%$, sendo que quando o tanque está vazio ou contém $50 \%$ de seu volume nominal a $4^{\circ} \mathrm{C}$ e então são acrescidos $50 \%$ do volume em uma batelada à $35^{\circ} \mathrm{C}$, todo o leite deve ser resfriado a $4^{\circ} \mathrm{C}$ sem ultrapassar o tempo de resfriamento específico. Com 4 ordenhas, as fases do tanque são: vazio, $25 \%, 50 \%, 75 \%$ e $100 \%$. Essa característica técnica influencia tanto o preço do equipamento, como o consumo de energia, consumo de material para limpeza do tanque, no valor de reposição do compressor, na estimativa do custo de manutenção e tempo de mão-de-obra requerida no processo.

Para estimar o efeito da estacionalidade de produção de leite do rebanho, que normalmente ocorre na atividade leiteira, considerou-se uma redução de $20 \%$ na produção total na época de seca, na região sudeste do país (abril a agosto). Para efeito de cálculo do custo unitário do litro de leite resfriado, utilizou-se a taxa anual de atratividade de $12 \%$ (HIRSCHFELD, 2000), vida útil de 15 anos para o tanque de resfriamento, de 20 anos para instalações e de 5 anos para o compressor. $\mathrm{O}$ tempo de vida útil do compressor e do tanque de resfriamento foi obtido junto aos fornecedores. Para cada tipo de tanque de resfriamento, no processo de 2 ou 4 ordenhas, foi calculado o custo uniforme líquido equivalente $(C U L)$ total por litro de leite, ou, custo total unitário, representado pela soma do custo operacional e do custo de investimento (HIRSCHFELD, 2000). O custo operacional é uma somatória dos custos uniformes equivalentes provindos das despesas com mãode-obra, energia elétrica e manutenção do tanque de resfriamento e do compressor (detergente alcalino, reposição de gás e controlador de temperatura). $\mathrm{O}$ custo de investimento é composto pelos custos uniformes líquidos equivalentes do tanque de resfriamento, do compressor e das instalações, que foram calculados a partir de conceitos da engenharia econômica. De acordo com Hirschfeld (2000), quando utilizam-se equipamentos, existem diversas alternativas em que defrontam-se os custos dos equipamentos com suas vidas úteis, os valores residuais por ocasião das vendas e as despesas anuais com mão-de-obra, energia e manutenção. Para confrontar essas alternativas, comparam-se os custos uniformes líquidos equivalentes, representados pela fórmula:

$$
C U L=(P-F)(U / P, i, n)+F i,
$$

onde,

$\mathrm{P}=$ custo inicial

$\mathrm{F}=$ valor residual

$\mathrm{i}=$ taxa de atratividade

$\mathrm{n}=$ vida útil

$(\mathrm{U} / \mathrm{P}, \mathrm{i}, \mathrm{n})=\underline{\mathrm{i}(1+\mathrm{i})^{\mathrm{n}}}$

$$
(1+\mathrm{i})^{\mathrm{n}}-1
$$

Os dados de capacidade do tanque de expansão (x $=300,500,800,1000,1020,1500,2000,3000,4000,5000$, 5900) e de custo unitário (y) foram submetidos à análise de variância (ANOVA), teste $\mathrm{F}$ e regressão, a $5 \%$ de significância, adotando modelo potencial $\left(\mathrm{y}=\mathrm{ax}^{\mathrm{b}}\right)$, para cada processo de enchimento do tanque, com duas ou quatro ordenhas.

\section{RESULTADOS E DISCUSSÃO}

Pelos resultados de regressão referentes às informações coletadas, evidencia-se pela Figura 1, a economia de escala presente no processo de resfriamento do leite cru tipo B, para a situação de operação com 2 ordenhas e na Figura 2 a economia de escala no sistema que trabalha com 4 ordenhas, para o enchimento do tanque. O custo unitário reduz, tanto para o sistema de enchimento 
do tanque com duas $\left(\mathrm{y}=0,42 \mathrm{x}^{-0,46}\right)$ ou quatro $\left(\mathrm{y}=0,86 \mathrm{x}^{-0,51}\right)$ ordenhas, em relação à capacidade do tanque (x). Independentemente da capacidade do tanque, o processo com 2 ordenhas apresenta um custo unitário menor, interpretado pelo coeficiente $a=0,42$ da curva $y=0,42 x^{-0,46}$.

Quando comparados os custos entre os modelos de tanque de um mesmo sistema de trabalho, verifica-se que no sistema de enchimento do tanque com 2 ordenhas, houve uma redução de $75 \%$ do custo total entre os tanques com capacidade de 300 e 5900 litros. No sistema de enchimento do tanque com 4 ordenhas essa redução de custo foi de $78 \%$. No entanto, quando confrontam-se os custos do resfriamento do leite em tanques com capacidades de 800 litros e de 2000 litros, observa-se que a variação apresenta queda mais acentuada (63\%) no sistema que trabalha com o enchimento dos tanques com 2 ordenhas (Figura 1) em relação ao sistema de 4 ordenhas (41\%). Na comparação entre os sistemas, o processo de enchimento de tanque com 2 ordenhas pressupõe a coleta diária do leite, enquanto que, no enchimento com 4 ordenhas, a coleta ocorre em dias alternados, para um mesmo modelo de tanque de expansão. O sistema com 2 ordenhas permite à fazenda trabalhar com uma produção anual de leite maior, por isso os custos totais unitários,

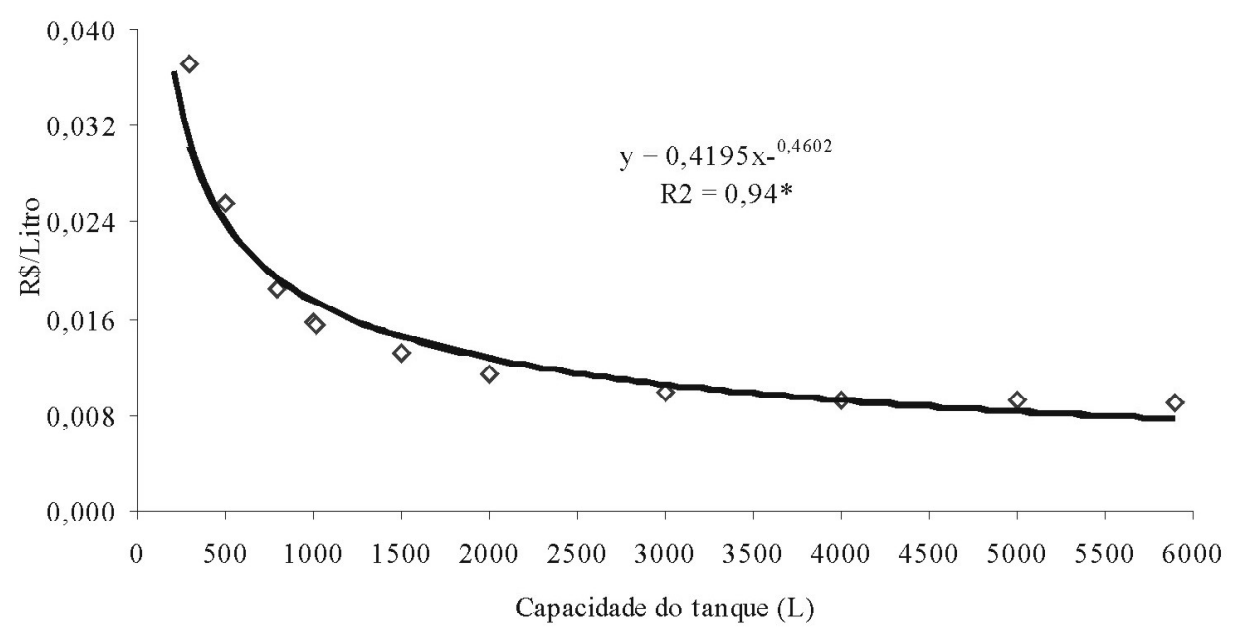

Figura 1 - Custo total unitário do processo de resfriamento do leite cru tipo B na propriedade rural - enchimento do tanque com 2 ordenhas. * significativo a $5 \%$.

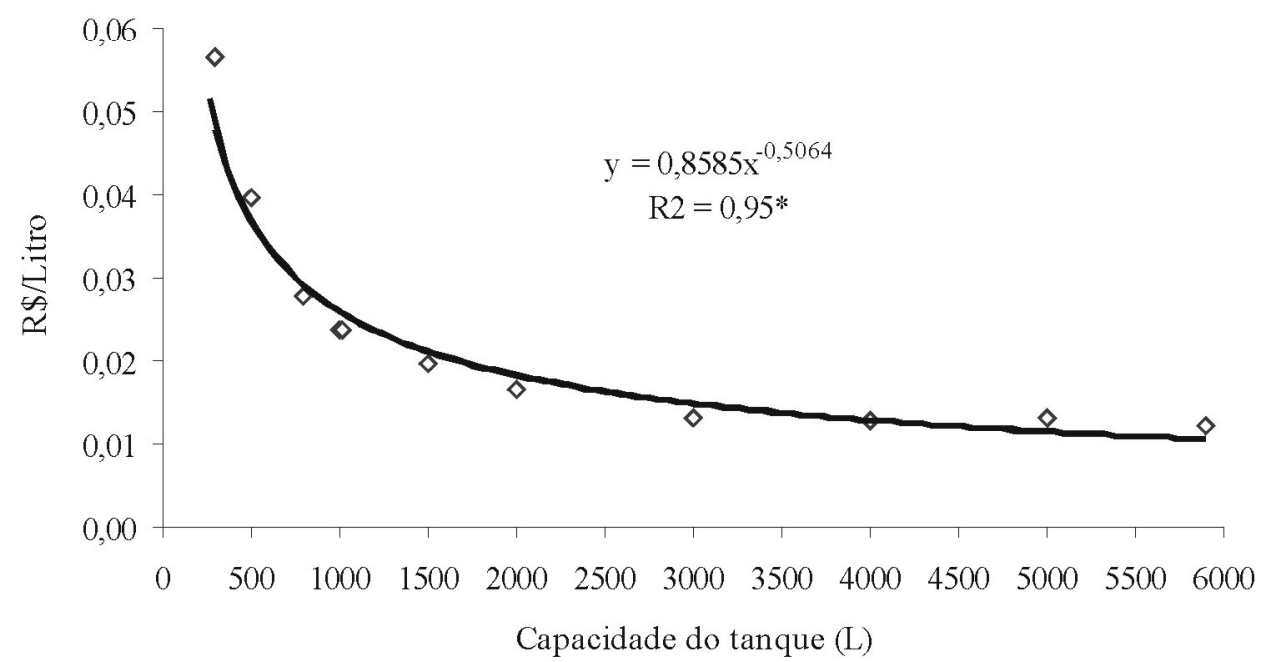

Figura 2 - Custo total unitário do processo de resfriamento do leite cru tipo B na propriedade rural - enchimento do tanque com 4 ordenhas. * significativo a $5 \%$. 
nessa situação, é menor. Considerando uma propriedade rural com uma produção anual em torno de 165.000 litros de leite, essa propriedade poderia trabalhar com um tanque de expansão de 500 litros para ser abastecido com o leite de 2 ordenhas ou com um tanque de 1000 litros para ser abastecido com o leite de 4 ordenhas. O primeiro modelo de tanque, apresentou um custo total unitário do processo de resfriamento do leite, na propriedade, de $\mathrm{R} \$ 0,02561 /$ litro de leite, enquanto que o segundo modelo obteve o custo total unitário de R $\$ 0,02373 /$ litro de leite. Agrega-se que a coleta do leite em dias alternados pode conferir ao produtor o benefício da redução do custo do transporte do leite da propriedade rural até a indústria.

Outros estudos sobre custos de produção na atividade leiteira também verificaram economias de escala. Lopes et al. (2007) evidenciaram a ocorrência de ganhos com a escala de produção, tendo em vista a redução dos custos médios para maiores níveis de produção, bem como os indicadores de rendimentos à escala crescentes e de economias de escala, indicando ganhos com o crescimento da produção de leite. No trabalho de Gomes \& Ferreira Filho (2007) os resultados da regressão revelaram que a grande maioria dos produtores de leite da amostra analisada estavam na faixa de economias de escala, sendo que apenas 3,4\% desses estavam na faixa de deseconomias de escala.

As Figuras 3 e 4 indicam a importância do custo operacional e de investimento na composição do custo total unitário, para o processo de resfriamento do leite realizado em tanques com capacidade para 2 e para 4 ordenhas, respectivamente.

Na primeira situação, quando eleva-se a capacidade do tanque de resfriamento de 300 para 5.900 litros de leite, obtém-se a redução do custo do investimento por litro de leite em $66 \%$, enquanto que o custo operacional apresenta uma redução de $80 \%$. Em termo absoluto, o custo operacional representa $54 \%$ do custo total unitário.

No caso de 4 ordenhas, quando a capacidade do tanque de resfriamento passa de 300 para 5.900 litros de leite, a redução do custo de investimento, por litro de leite, é de $71 \%$ e do custo operacional é de $83 \%$. O custo operacional representa $45 \%$ do custo total unitário. Embora existam custos operacionais que não se alteram com a aquisição de tanques de capacidade mais elevada, como a despesa com o controlador de temperatura e a visita do técnico na propriedade rural, as despesas com a reposição do gás, mão-de-obra e consumo de energia variam em função do tamanho do tanque de expansão. $\mathrm{O}$ item que mais se alterou foi o consumo de energia que, no sistema de enchimento do tanque com 2 ordenhas, obteve uma elevação de consumo de energia de $94,5 \%$ quando comparado o modelo de 300 litros com o de 5900 litros. Na situação do enchimento do tanque com 4 ordenhas, esse aumento de consumo foi de $92 \%$. Ainda comparando essas capacidades de tanque, o item energia representava $12 \%$ e

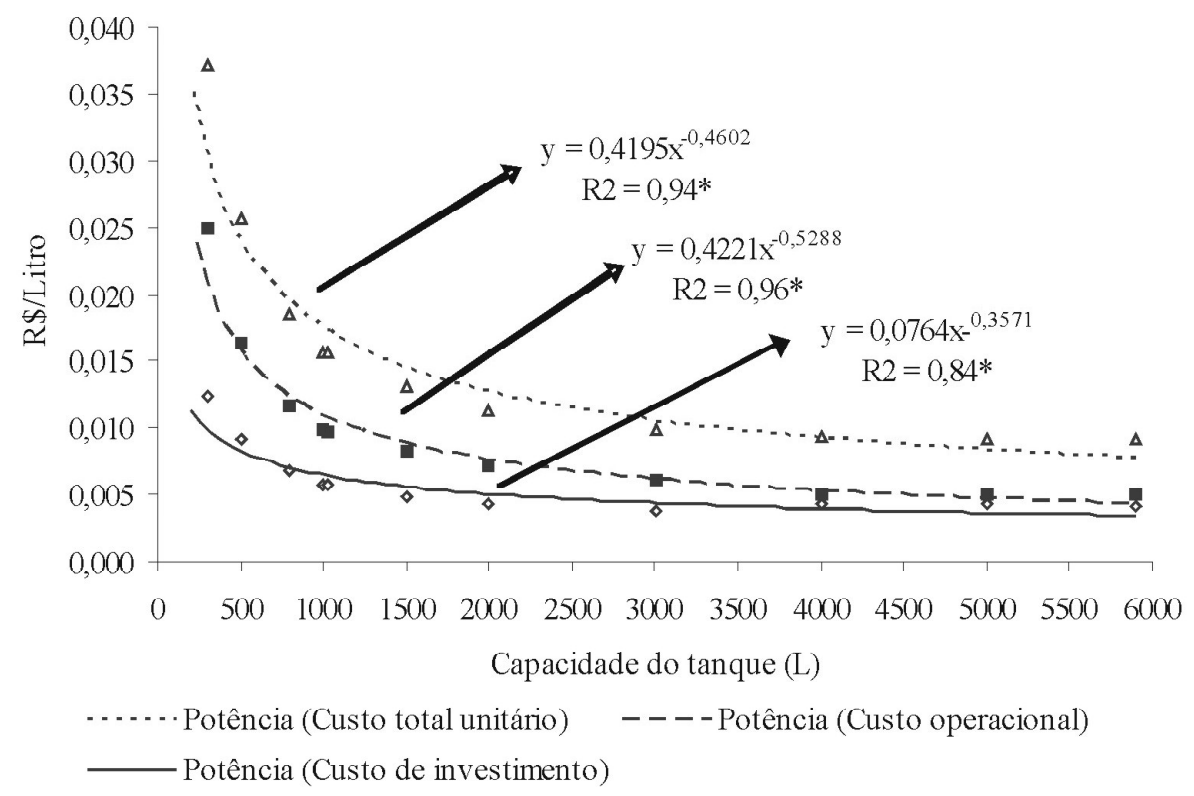

Figura 3 - Custo operacional, custo de investimento e custo total em termos unitários para o enchimento do tanque em 2 ordenhas. * significativo a $5 \%$. 


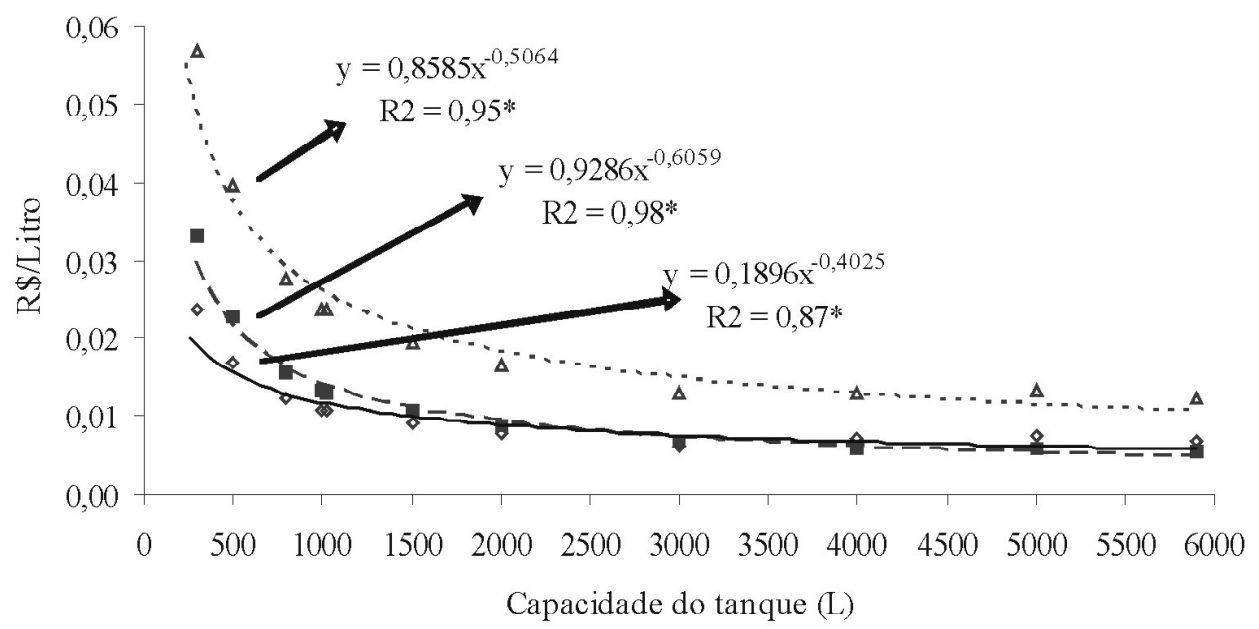

\footnotetext{
-... - Potência (Cus to total unitário)

- Potência (Custo de investimento)
}

---- Potência (Custo operacional)

Figura 4 - Custo operacional, custo de investimento e custo total em termos unitários para o enchimento do tanque em 4 ordenhas. * significativo a $5 \%$.

$13 \%$ do custo operacional e passou para $54 \%$ e $50 \%$ do custo operacional, nos tanques com enchimento com 2 e 4 ordenhas, respectivamente. Com o item mão-de-obra o comportamento foi inverso, quanto maior a capacidade do tanque de expansão, menor a participação relativa desse item na composição do custo operacional. Esse item passou de $49 \%$ e $37 \%$ do custo operacional para $19 \%$ e $17 \%$ do custo operacional, nos tanques com enchimento com 2 e 4 ordenhas, respectivamente. Na composição do custo de investimento, o tanque de expansão tem maior participação porcentual e ela eleva-se em $10 \%$ com o aumento do tamanho do tanque de 300 para 5900 litros, em ambas as situações.

$\mathrm{Na}$ análise qualitativa do processo de resfriamento do leite observou-se economia de escala real relacionada com o tamanho do equipamento industrial utilizado, no caso, a aquisição do tanque de resfriamento do leite. Essa fonte de economia de escala diz respeito às propriedades geométricas do tanque, ou seja, ao tamanho do equipamento industrial. Nessas situações, os custos não crescem na mesma proporção que o crescimento da capacidade/volume do tanque. O produto desses equipamentos tende a ser proporcional ao seu volume, enquanto que o custo de produção está associado à área de superfície das unidades processadoras (HALDI \& WHITCOMB, 1967, citados por KUPFER \& HASENCLEVER, 2002). Estudos apresentados por Kupfer \& Hasenclever (2002), concluíram que, quanto maior a capacidade produtiva do equipamento, menores são os custos de aquisição associados. Ressalta-se que esse resultado não implica que os custos médios de longo prazo declinem com a quantidade produzida, mas sejam reduzidos com a compra de equipamentos com maior capacidade.

Ainda nas fontes de economias de escala reais no processo de resfriamento do leite na propriedade rural, verificou-se que alguns custos de manutenção como: (i) a reposição do controlador de temperatura; e, (ii) a visita do técnico para reposição do compressor e da reposição do gás, são custos que não se alteram proporcionalmente à escala de produção (ARAÚJO, 2003). Observou-se ainda tendência de economia de escala decorrente da redução no uso proporcional do insumo energia elétrica, conforme aumenta-se a escala de produção, em especial, no uso de equipamentos destinados a operar com quatro ordenhas para completar a capacidade do tanque.

Embora não tenha sido quantificado neste trabalho, em entrevista com um representante da cooperativa de leite verificou-se que houve a redução do custo de transporte do leite da propriedade rural até a indústria, após a implantação da Instrução Normativa 51. Isso foi possível devido à integração vertical do processo de resfriamento do leite na propriedade rural, que, utilizando tanques abastecidos por 4 ordenhas, propiciou a coleta do leite a cada 2 dias pela cooperativa, ao invés da coleta diária. Com isso, além da melhoria da qualidade do produto, obteve-se benefícios na redução do custo de coleta e transporte do leite. Melo (2003) também evidenciou que o 
sistema de granelização permitiu a redução dos custos de frete, a redução de custos operacionais na recepção do leite e a redução de custos de manutenção de equipamentos para o segmento da indústria.

$\mathrm{Na}$ propriedade rural em estudo, o funcionário responsável pela ordenha relatou que houve significativa redução do tempo de mão-de-obra despendida no processo de armazenamento e coleta do leite após a adoção do tanque de resfriamento do leite automatizado, quando comparado com o sistema de coleta do leite em latão. Da mesma forma, Melo (2003) verificou que a agilidade do processo e a redução da mão-de-obra foram melhorias apontadas pela indústria após a adoção do sistema de granelização.

\section{CONCLUSÕES}

O estudo indicou a tendência a economias de escala no processo de resfriamento do leite e que os retornos crescentes são decorrentes, tanto do menor custo unitário de investimento, quanto do custo unitário operacional. Tanto a utilização de modelos de tanque de expansão para enchimento com 2 ordenhas quanto com 4 ordenhas apresentaram redução do custo total unitário de $75 \%$ e $78 \%$, respectivamente, na comparação entre o tanque de capacidade de 300 litros e o de 5900 litros. No entanto, na avaliação de um trecho da curva exponencial negativamente inclinada, entre os tanques com capacidade de 800 litros e de 2000 litros, a utilização de tanques para 2 ordenhas apresentou queda mais acentuada. Na comparação entre os sistemas de enchimento do tanque, a partir de 2 ou de 4 ordenhas e a mesma produção anual de leite, a utilização do tanque para enchimento em 4 etapas apresentou vantagens.

\section{REFERÊNCIAS BIBLIOGRÁFICAS}

ARAÚJO, J. B. Economias de escala em duas tecnologias alternativas: um estudo do setor siderúrgico. 2003. 100 p. Dissertação (Mestrado) - Universidade Federal de São Carlos, São Carlos, 2003.

AZEVEDO, P. F. Organização industrial. In: MONTORO, F. A. F. Manual de economia. 3. ed. São Paulo: Saraiva, 1998. cap. 8.
BAIN, J. Barriers to new competition. Campinas: IEUnicamp, 1956. Mimeografado.

BRASIL. Ministério da Agricultura, Pecuária e Abastecimento. Instrução Normativa 51, de 18 de setembro de 2002. Diário Oficial [da] União, Brasília, DF, 20 set. 2002. Seção 1, p. 13.

CARVALHO, L. B.; AMARAL, F. R.; BRITO, M. A. V. P.; LANGE, C. C.; BRITO, J. R. F.; LEITE, R. Contagem de células somáticas e isolamento de agentes causadores de mastite em búfalas (Bubalus bubalis). Arquivo Brasileiro Medicina Veterinária e Zootecnia, Belo Horizonte, v. 59, n. 1, p. 242-245, 2007.

CHANDLER, A. D. Scale and scope: the dynamics of industrial capitalism. Cambridge: Harvard University, 1990.

FAGUNDES, H.; OLIVEIRA, C. A. F. Infecções intramamárias causadas por Staphylococcus aureus e suas implicações em saúde pública. Ciência Rural, Santa Maria, v. 34, n. 4, p. 1315-1320, 2004.

GOMES, A. L.; FERREIRA FILHO, J. B. S. Economias de escala na produção de leite: uma análise dos estados de Rondônia, Tocantins e Rio de Janeiro. Revista de Economia e Sociologia Rural, v. 45, n. 3, p. 591-619, jul./set. 2007.

HIRSCHFELD, H. Engenharia econômica e análise de custos. São Paulo: Atlas, 2000.

KUPFER, D.; HASENCLEVER, L. Economia industrial. Rio de Janeiro: Campus, 2002.

LOPES, P. F.; REIS, R. P.; YAMAGUCHI, L. C. T. Custos e escala de produção na pecuária leiteira: estudo nos principais estados produtores do Brasil. Revista de Economia e Sociologia Rural, v. 45, n. 3, p. 567-590, jul./ set. 2007.

MELO, A. D. S. Experiência associativa para aquisição e uso de tanques de expansão e resfriamento de leite. 2003. 139 p. Dissertação (Mestrado) - Universidade Federal de Lavras, Lavras, 2003. 